\title{
Depression and Prescription Opioid Misuse Among Chronic Opioid Therapy Recipi- ents With No History of Substance Abuse
}

\author{
Alicia Grattan, $M D^{1}$ \\ Mark D. Sullivan, $M D, P b D^{1}$ \\ Katbleen W. Saunders, JD² \\ Cyntbia I. Campbell, $P b D, M P H^{3}$ \\ Michael R. Von Korff, ScD ${ }^{2}$ \\ 'Department of Psychiatry \& Behavioral \\ Sciences, University of Washington School \\ of Medicine, Seattle, Washington
}

${ }^{2}$ Group Health Research Institute, Seattle, Washington

${ }^{3}$ Kaiser Permanente, Oakland, California

Conflicts of interest: authors report none.

\section{CORRESPONDING AUTHOR}

Mark Sullivan, MD, PhD

Department of Psychiatry \& Behavioral

Sciences

Box 356560

University of Washington School of

Medicine

Seattle, WA 98195-6560

sullimar@uw.edu

\begin{abstract}
PURPOSE Opioid misuse in the context of chronic opioid therapy (COT) is a growing concern. Depression may be a risk factor for opioid misuse, but it has been difficult to tease out the contribution of co-occurring substance abuse. This study aims to examine whether there is an association between depression and opioid misuse in patients receiving COT who have no history of substance abuse.
\end{abstract}

METHODS A telephone survey was conducted at Group Health Cooperative and Kaiser Permanente of Northern California. We interviewed 1,334 patients on COT for noncancer pain who had no history of substance abuse. Patients were asked about 3 forms of opioid misuse: (1) self-medicating for symptoms other than pain, (2) self-increasing doses, and (3) giving to or getting opioids from others. Depression was evaluated by the 8-item Patient Health Questionnaire (PHQ-8).

RESULTS Compared with patients who were not depressed (PHQ-8 score 0 to 4), patients with moderate depression (PHQ-8 score 10 to 14 ) and severe depression (PHQ-8 score 15 or higher) were 1.8 and 2.4 times more likely, respectively, to misuse their opioid medications for non-pain symptoms. Patients with mild (PHQ-8 score 5 to 9), moderate, and severe depression were 1.9, 2.9, and 3.1 times more likely, respectively, to misuse their opioid medications by self-increasing their dose. There was no statistically significant association between depression and giving opioids to or getting them from others.

CONCLUSION In patients with no substance abuse history, depressive symptoms are associated with increased rates of some forms of self-reported opioid misuse. Clinicians should be alert to the risk of patients with depressive symptoms using opioids to relieve these symptoms and thereby using more opioids than prescribed.

Ann Fam Med 2012;10:304-311. doi:10.1370/afm.1371.

\section{INTRODUCTION}

$\mathrm{P}$ rescription of opioid medications for the treatment of chronic noncancer pain has become common. Chronic opioid therapy (COT) is complicated by balancing pain relief with the risk of misuse. Prescription opioids are the fastest growing form of drug abuse and the most common cause of unintentional overdose. ${ }^{1,2}$ Misuse of prescribed opioids may be an important link between rising rates of opioid-related abuse and overdoses. ${ }^{3,4}$

The National Institute for Drug Abuse defines prescription opioid misuse as "taking a medication in a manner other than that prescribed or for a different condition than that for which the medication is prescribed." ${ }^{\text {"5 }}$ Other definitions of opioid misuse exist. The addiction literature often focuses on such aberrant behavior as giving opioid medications to or getting them from others. ${ }^{6,7}$ In primary care settings, misuse is often defined as nonadherence, generally meaning taking more medication than prescribed and asking for early refills. ${ }^{8}$ The National Institute for Drub Abuse definition also encompasses taking opioids for symptoms other than pain. ${ }^{9}$ 
Depression complicates the management of chronic pain. ${ }^{10-12}$ Research has shown that patients with depression are more likely to receive COT., ${ }^{3,13-18}$ Some evidence suggests that a mental health diagnosis may be

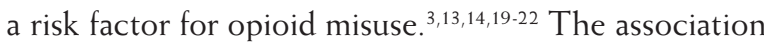
between a mental health diagnosis and opioid misuse may be due to comorbid substance use disorders (SUDs), as a history of substance abuse is the most consistent predictor of both COT use and misuse. ${ }^{15,16,19,20}$ In one study, rates of COT use for chronic noncancer pain among individuals with SUDs were 4 times higher than for those without SUDs. Patients with SUDs were also more likely to receive higher doses, more days' supply, and more-potent opioids. ${ }^{23}$ Another study found that SUDs were associated with a 6.6 times increased rate of borrowing opioid medications and a 3.7 times increased rate of requesting early refills. ${ }^{7}$ Because the risks of opioid misuse associated with SUDs are well-documented, we focused on the relationship between depression and misuse among those without SUDs.

The primary objective of this study was to better characterize the relationship between depression and self-reported opioid misuse among patients with no history of SUDs who were receiving COT for chronic noncancer pain. We examined the following misuse behaviors: (1) using opioids for stress or sleep, (2) using more opioids than prescribed and/or requesting early refills, and (3) sharing opioids with or receiving them from others. We hypothesized that depressed patients would be more likely to use opioids for non-pain symptoms and take more medication than prescribed. With no known SUD in this population, we suspected that there would be no association between depression and giving or getting opioids. A secondary objective of this study was to identify other clinical variables associated with misuse.

\section{METHODS}

The CONSORT study (CONsortium to Study Opioid Risks and Trends), funded by the National Institute for Drug Abuse, was initiated to study COT for chronic noncancer pain among adults. The study took place at Group Health Cooperative (GHC) in Washington State and Kaiser Permanente of Northern California (KPNC). Together, these health plans serve approximately 4 million people. The study was reviewed and approved by the Institutional Review Boards at both sites.

\section{Inclusion and Exclusion Criteria}

Data were collected during a single telephone interview of COT patients. To be eligible for the survey, GHC and KPNC members aged between 21 and 80 years must have filled at least 10 opioid prescriptions or received at least a 120-day supply in the year before the interview. In addition, at least 90 days must have elapsed between the first and last opioid dispensing in that year. These criteria for long-term opioid use have been shown to predict a high probability of sustained opioid use 1 year later. ${ }^{24}$ Opioid usage was ascertained through the institutions' electronic pharmacy databases, which capture $90 \%$ of prescription medications used by members. ${ }^{25,26}$

To tease out the contribution of depression from substance abuse, we excluded patients with a known SUD from the current analysis. Patients were excluded if they responded "yes" to the following interview question: "Have you ever had an alcohol or drug problem?" Similarly, patients were excluded if they received a diagnosis of drug or alcohol abuse or dependence in the 3 years before the interview according to automated diagnosis data.

The current analysis is restricted to those patients who reported using opioid medications in the last 2 weeks. All CONSORT patients were required to be continuously enrolled in either GHC or KPNC 1 year before sampling. Patients who received a cancer diagnosis (according to Western Washington Cancer and Surveillance Epidemiology and End Results registries), except skin cancer other than melanoma, or who had 2 or more cancer diagnoses according to the automated visit records in the year before sampling were excluded from the CONSORT study.

\section{Sampling}

Patients were selected using stratified sampling, selecting equal numbers of patients within 3 dosage strata ( 1 to $49 \mathrm{mg}$, 50 to $99 \mathrm{mg}$, and $100 \mathrm{mg}$ or more, morphine-equivalent dose). The morphine-equivalent dose for each opioid prescription was calculated by multiplying the quantity of the prescription by the strength (milligrams per unit dispensed) and then by a conversion factor. ${ }^{27}$ Means, variances, proportions, and other estimates reported in this article were obtained using estimation methods for a stratified random sample.

\section{Telephone Survey Procedures}

At GHC, interviews were conducted between June 2008 and November 2008. At KPNC, interviews were conducted from January 2009 to October 2009. A letter explaining the study was mailed to potentially eligible patients. Potential GHC respondents received a $\$ 2$ bill with the letter; KPNC members received a $\$ 5$ gift card for a national retail store. Potential respondents were then called by survey interviewers in the collaborating health plan research centers. Patients were asked to take part in a 30-minute telephone interview, which was conducted using computer-assisted telephone interview 
technology. Patients were also asked to allow study staff to access electronic medical data from the time they enrolled in the health plan until 3 years after the date of the interview. Patients who completed the interview at $\mathrm{GHC}$ were mailed $\$ 20$ cash reimbursement, whereas those at KPNC who completed the interview received a $\$ 50$ gift card reimbursement. The differential incentive payments reflected the researchers' prior experience with achieving acceptable response rates at their institutions.

\section{Assessment of Misuse}

Three different types of misuse were determined presumptively: non-pain symptoms (using opioids for stress or sleep), nonadherence (self-increasing dose or early refills), and aberrant behavior (giving opioids to or getting them from others). Two face-valid questions were used to evaluate each type of misuse. Misuse for non-pain symptoms was assessed by responses to these questions: (1) "In the past 2 weeks, how often did you use an opiate medicine to help calm your nerves or to give yourself a break from stress?" and (2) "In the past 2 weeks, how often did you take opiate medicine in order to help you sleep at night?" Nonadherence was classified by answers to these questions: (1) "In the past 2 weeks, how often did you use more opiate medicine than your doctor prescribed in order to control your pain?" and (2) "In the past year, about how many times did you have to request an early refill because you ran out or because you lost or misplaced your opiate pain medicine?" Aberrant behavior was determined by responses to these questions: (1) "In the past year, about how many times did you give some of your opiate medicines to a relative or friend?" and (2) "In the past year, about how many times did a relative or friend give you some of their opiate medicine?" A patient was classified as negative on a specific misuse type if she or he responded "never" to both items comprising the scale; otherwise, a patient was considered to be positive for that type of misuse.

\section{Depression Measure}

Depressive symptoms during the past 2 weeks were measured with the 8-item version of the Patient Health Questionnaire (PHQ-8), a validated self-report measure of depression. ${ }^{28}$ The PHQ- 8 is the same as PHQ-9 minus the question about suicidal ideation. PHQ-9 scoring cut-offs were used. Scores of 0 to 4 were classified as not depressed, 5 to 9 as mild depression, 10 to 14 as moderate depression, and 15 and higher as severe depression.

\section{Statistical Analyses}

All reported analyses were weighted to adjust for the differences in sample selection probabilities by average daily dose as calculated from the electronic pharmacy data. SAS PROC SURVEYMEANS and PROC SURVEYREG software (SAS/STAT 9.2, SAS Institute Inc) was used to account for the stratified random sampling approach, providing estimates for the population surveyed. Basic statistics were used to describe patients surveyed. Adjusted odds ratios were calculated for the relationship of depression (PHQ-8, 0 to 4 points [reference], 5 to 9 points, 10 to 14 points, and 15 points and higher) to the positive misuse score using categorical logistical regression. The covariates in the adjusted model included age, sex, education, race, marital status, average pain severity, ${ }^{29}$ morphine-equivalent dose (1 to $49 \mathrm{mg}$, 50 to $99 \mathrm{mg}$, and $100 \mathrm{mg}$ and higher), and survey site (GHC and KPNC). Pain severity was assessed by asking patients to rate their pain using a scale ranging from 0 to 10 , in which 0 is "no pain" and 10 is "pain as bad as could be."

\section{RESULTS}

\section{Survey Participation}

At GHC, 2,185 patients were approached of whom 2,109 were considered eligible; among these eligible patients, 1,191 completed the interview. At KPNC, 1,605 persons were approached of whom 1,496 were considered eligible; among these eligible patients, 972 completed the interview. The total number of completed interviews was 2,163, for an overall response rate of $60 \%$ (57\% at GHC and $65 \%$ at KPNC). The sample population examined here excluded patients with SUDs and those who had not used opioids in the past 2 weeks, which reduced the total completed interviews to 1,334 (776 from GHC and 558 from KPNC).

\section{Descriptive Results}

Table 1 displays the demographic and clinical characteristics of the 1,334 survey respondents. Respondents were more frequently middle-aged, white, married, and female. Average pain severity ranged most frequently from 3 to 5 . The majority had a PHQ-8 score of less than 10 .

\section{Misuse, Depression, and Other Demographic and Clinical Characteristics}

Table 2 compares rates of positive misuse by demographic and clinical information. A higher percentage of misuse for non-pain symptoms and aberrant behavior was observed with lower daily dose and less education. Male sex and GHC site were also associated with higher percentages of misuse for non-pain symptoms. Increased pain severity was associated with nonadherence. Younger age was associated with nonadherence and aberrant behavior. Higher percentages of aberrant behavior were observed in whites. 


\section{Table 1. Sample Characteristics $(\mathrm{N}=1,334)$}

\begin{tabular}{|c|c|c|}
\hline Variable & $\begin{array}{c}\text { No. } \\
\text { (Unweighted) }\end{array}$ & $\begin{array}{c}\% \\
\text { Weighted }\end{array}$ \\
\hline \multicolumn{3}{|l|}{ Age, y } \\
\hline $18-44$ & 249 & 16.8 \\
\hline $45-64$ & 798 & 60.6 \\
\hline$\geq 65$ & 287 & 22.7 \\
\hline Sex, female, \% & 907 & 69.0 \\
\hline \multicolumn{3}{|l|}{ Race } \\
\hline African American & 102 & 7.7 \\
\hline White & 1,120 & 83.6 \\
\hline Asian & 24 & 1.3 \\
\hline Other & 88 & 7.4 \\
\hline \multicolumn{3}{|l|}{ Marital status } \\
\hline Married/living as married & 886 & 65.3 \\
\hline Never married & 144 & 11.0 \\
\hline Widowed & 91 & 7.3 \\
\hline Separated/divorced & 217 & 16.5 \\
\hline \multicolumn{3}{|l|}{ Education } \\
\hline Less than high school & 79 & 5.0 \\
\hline $\begin{array}{l}\text { High school graduate/ } \\
\text { trade school }\end{array}$ & 419 & 32.2 \\
\hline Some college & 543 & 40.4 \\
\hline College graduate & 293 & 22.3 \\
\hline \multicolumn{3}{|l|}{ PHQ-8 score } \\
\hline $0-4$ & 341 & 31.2 \\
\hline $5-9$ & 388 & 31.1 \\
\hline $10-14$ & 299 & 19.6 \\
\hline$\geq 15$ & 305 & 18.1 \\
\hline \multicolumn{3}{|l|}{$\begin{array}{l}\text { Average daily morphine- } \\
\text { equivalent dose }\end{array}$} \\
\hline$<50 \mathrm{mg}$ & 509 & 71.0 \\
\hline $50-99 \mathrm{mg}$ & 414 & 16.6 \\
\hline$\geq 100 \mathrm{mg}$ & 416 & 12.4 \\
\hline \multicolumn{3}{|l|}{ Health plan site } \\
\hline $\mathrm{GHC}$ & 776 & 60.2 \\
\hline KPNC & 558 & 39.2 \\
\hline \multicolumn{3}{|l|}{ Average pain severity ${ }^{b}$} \\
\hline $0-2$ & 36 & 3.4 \\
\hline $3-5$ & 551 & 46.4 \\
\hline $6-7$ & 464 & 30.8 \\
\hline$\geq 8$ & 282 & 19.4 \\
\hline
\end{tabular}

$\mathrm{GHC}=$ Group Health Cooperative; KPNC = Kaiser Permanente of Northern California; PHQ-8 $=8$-item version of the Patient Health Questionnaire.

a Scored on a scale in which 0-4 = no, 5-9 = mild, 10-14 = moderate, and $\geq 15$ = severe depression.

b Scored on a range from 0-10 in which a higher score indicates worse pain.

Table 3 displays the adjusted relationship between depression and other clinical characteristics with respect to misuse for non-pain symptoms. Patients with moderate and severe depressive symptoms were 1.75 $(P=.031)$ and $2.42(P=.001)$ times more likely, respectively, to misuse their opioid medications for non-pain symptoms than were patients who were not depressed.

Table 4 displays the adjusted relationship between depression and other clinical factors in terms of nonadherence. Patients with mild, moderate, and severe depressive symptoms were $1.93(P<.001), 2.89$ $(P<.001)$, and $3.13(P<.001)$ times more likely, respectively, to use more opioids than prescribed compared with patients who were not depressed.

Table 5 examines the adjusted relationship between depression and other clinical information with respect to aberrant behavior misuse. There was no statistically significant association between depressive symptoms and giving opioids to or getting them from others.

Figure 1 displays patients scoring positive on the 3 misuse measures according to depression score. For non-pain symptoms, $36.9 \%$ of patients without depression misused compared with $40.2 \%$ of patients with mild, $47.2 \%$ with moderate, and $51.8 \%$ with severe depression. For nonadherence, $27.3 \%$ of patients without depression misused in contrast to depressed patients: $42.6 \%$ (mild), 54.3\% (moderate), and $57.7 \%$ (severe). The percentage of positive misuse for aberrant behavior was $15.5 \%$ for no depression and $12.3 \%$ for mild, $23.4 \%$ for moderate, and $24.5 \%$ for severe depression.

\section{DISCUSSION}

\section{Opioid Misuse and Depression}

This study found that depression in the absence of substance abuse is significantly associated with 2 forms of self-reported prescription opioid misuse as defined by (1) using opioids for stress or sleep and (2) using more opioids than prescribed. This relationship persisted after controlling for relevant demographic and clinical factors. A dose-response relationship was evident, with more severe depression showing a stronger association with these forms of misuse. No significant association was noted between depression and giving opioids to or getting them from others. These results begin to clarify the types of opioid misuse associated with depression among patients without SUDs.

According to a recent review, estimates of the prevalence of opioid misuse among recipients of COT vary widely, from $3 \%$ to $62 \%{ }^{30}$ This finding is likely a result of differences in source populations (many studies excluded mental health diagnoses and SUDs) and varying definitions of misuse. Previous research using urine toxicology screens have found prevalence rates of opioid misuse ranging from $20 \%$ to $40 \% .{ }^{31}$ Rates of misuse reported in our study varied depending on the type of misuse examined and the severity of depressive symptoms, which ranged from $12.3 \%$ to $57.7 \%$. In our study, patients who were not depressed had lower rates of opioid misuse overall, peaking at $36.9 \%$ for non-pain symptoms. 
It is difficult to tease out a causal relationship between opioid misuse and depression. It is possible that opioid misuse produces depression, eg, by increasing apathy and lethargy. Alternatively, opioids are known to have independent anxiolytic and mood-alter-

\section{Table 2. Number (Unweighted) and Weighted Percentage of Patients Scoring Positive on 3 Misuse Types by Demographic and} Clinical Characteristics

\begin{tabular}{|c|c|c|c|c|c|c|}
\hline \multirow[b]{2}{*}{ Variable } & \multicolumn{2}{|c|}{$\begin{array}{l}\text { Non-Pain } \\
\text { Symptoms }\end{array}$} & \multicolumn{2}{|c|}{ Nonadherence } & \multicolumn{2}{|c|}{$\begin{array}{l}\text { Aberrant } \\
\text { Behavior }\end{array}$} \\
\hline & No. & $\%$ & No. & $\%$ & No. & $\%$ \\
\hline \multicolumn{7}{|l|}{ Age, y } \\
\hline $18-44$ & 91 & 47.3 & 144 & 59.0 & 57 & 27.8 \\
\hline $45-64$ & 299 & 41.5 & 356 & 39.6 & 113 & 16.7 \\
\hline$\geq 65$ & 118 & 42.1 & 106 & 39.9 & 34 & 12.7 \\
\hline \multicolumn{7}{|l|}{ Sex } \\
\hline Female & 328 & 39.6 & 404 & 42.3 & 145 & 18.3 \\
\hline Male & 180 & 49.7 & 202 & 44.3 & 59 & 16.2 \\
\hline \multicolumn{7}{|l|}{ Race } \\
\hline African American & 39 & 38.2 & 60 & 44.7 & 17 & 13.4 \\
\hline White & 426 & 38.1 & 493 & 43.0 & 174 & 18.7 \\
\hline Asian & 7 & 30.4 & 12 & 40.0 & 2 & 4.4 \\
\hline Other & 31 & 35.6 & 39 & 41.9 & 10 & 13.0 \\
\hline \multicolumn{7}{|l|}{ Marital status } \\
\hline Married/living as married & 347 & 45.6 & 394 & 42.6 & 132 & 18.4 \\
\hline Never married & 50 & 40.1 & 78 & 50.0 & 28 & 17.0 \\
\hline Widowed & 32 & 34.1 & 34 & 40.0 & 12 & 18.7 \\
\hline Separated/divorced & 79 & 36.5 & 99 & 42.1 & 31 & 13.8 \\
\hline \multicolumn{7}{|l|}{ Education } \\
\hline Less than high school & 37 & 59.7 & 32 & 39.1 & 10 & 15.9 \\
\hline $\begin{array}{l}\text { High school graduate/ } \\
\text { trade school }\end{array}$ & 179 & 49.6 & 195 & 44.9 & 67 & 21.7 \\
\hline Some college & 192 & 36.4 & 274 & 45.2 & 80 & 17.1 \\
\hline College graduate & 100 & 39.8 & 115 & 36.8 & 47 & 13.1 \\
\hline \multicolumn{7}{|l|}{ PHQ-8 score ${ }^{a}$} \\
\hline $0-4$ & 102 & 36.9 & 119 & 27.3 & 46 & 15.5 \\
\hline $5-9$ & 139 & 40.2 & 173 & 42.6 & 45 & 12.3 \\
\hline $10-14$ & 131 & 47.2 & 146 & 54.3 & 57 & 23.4 \\
\hline$\geq 15$ & 136 & 51.8 & 167 & 57.7 & 56 & 24.5 \\
\hline \multicolumn{7}{|l|}{$\begin{array}{l}\text { Average daily morphine- } \\
\text { equivalent dose }\end{array}$} \\
\hline$<50 \mathrm{mg}$ & 247 & 46.8 & 219 & 41.2 & 93 & 18.5 \\
\hline $50-99 \mathrm{mg}$ & 134 & 34.0 & 203 & 47.8 & 66 & 17.0 \\
\hline$\geq 100 \mathrm{mg}$ & 127 & 29.9 & 184 & 46.2 & 45 & 13.6 \\
\hline \multicolumn{7}{|l|}{ Health plan site } \\
\hline $\mathrm{GHC}$ & 324 & 46 & 432 & 42.1 & 103 & 16.3 \\
\hline KPNC & 184 & 37.4 & 264 & 44.2 & 101 & 19.6 \\
\hline \multicolumn{7}{|l|}{ Average pain severity } \\
\hline $0-2$ & 11 & 57.9 & 14 & 39.1 & 7 & 32.9 \\
\hline $3-5$ & 202 & 41.0 & 235 & 38.5 & 85 & 15.9 \\
\hline $6-7$ & 175 & 40.4 & 215 & 43.9 & 73 & 17.7 \\
\hline$\geq 8$ & 117 & 49.3 & 138 & 54.7 & 38 & 19.9 \\
\hline \multicolumn{7}{|c|}{$\begin{array}{l}\mathrm{GHC}=\text { Group Health Cooperative; KPNC = Kaiser Permanente of Northern California; PHQ-8 }=8 \text {-item ver } \\
\text { sion of the Patient Health Questionnaire. }\end{array}$} \\
\hline $\begin{array}{l}\text { a Scored on a scale in which } 0-4= \\
\text { b Scored on a scale ranging from }\end{array}$ & $5-9=$ & Id, 10-14 & noderate, & $\geq 15=\mathrm{sev}$ & depre & \\
\hline
\end{tabular}

ing properties that may prompt misuse in depressed patients. Historically, opioids have been used to treat psychological distress (mania and melancholia), as well as physical pain, ${ }^{32,33}$ and more recently studies have suggested using opioids for treatment-resistant depression and anxiety. ${ }^{34-37}$ It is also possible that depressed patients may experience their pain as more severe, which may prompt misuse. ${ }^{38}$

A recent study of elderly adults supports the association of current depressive symptoms and opioid misuse. ${ }^{39}$ Research has shown that patients with depression were more likely to initiate and continue opioid therapy than were patients who were not depressed.${ }^{18}$ In this article, we present evidence that patients with current depressive symptoms are more likely to take opioids for nonpain symptoms and to take extra medications. In contrast, behaviors that are arguably more aberrant, such as giving medications to or getting medications from others, may be limited to those with SUDs.

\section{Opioid Misuse and Other Risk Factors}

This study also sought to identify other risk factors for misuse. Risk factors for misuse for non-pain symptoms included male sex, lower average daily dose (which may be related to using more short-acting, as-needed opioids), less education, and being a member of GHC (which may be due to other socioeconomic factors). For nonadherence and aberrant behavior, younger age was identified as a risk factor, which has been identified previously.${ }^{19}$ Higher pain severity was also associated with increased nonadherence, which may reflect undertreatment of pain in accord with the pseudoaddiction theory. ${ }^{38,39}$ White race, less education, and lower daily dose were associated with increased aberrant behavior.

\section{Limitations}

Our study has several limitations. The 2-item questions for each type of misuse described in this study 


\begin{tabular}{|c|c|c|}
\hline Effect & OR $(95 \% \mathrm{Cl})$ & $\begin{array}{c}P \\
\text { Value }\end{array}$ \\
\hline \multicolumn{3}{|l|}{ PHQ-8 scores ${ }^{a}$} \\
\hline PHQ-8: $\geq 15$ vs $0-4$ & $2.42(1.46-4.02)$ & .001 \\
\hline PHQ-8: $10-14$ vs $0-4$ & $1.75(1.05-2.91)$ & .031 \\
\hline PHQ-8: $5-9$ vs $0-4$ & $1.23(0.80-1.90)$ & .346 \\
\hline Age & $1.00(0.98-1.01)$ & .80 \\
\hline Sex (female vs male) & $0.56(0.39-0.80)$ & .002 \\
\hline Race (nonwhite vs white) & $1.36(0.87-2.12)$ & .17 \\
\hline $\begin{array}{l}\text { Marital status (nonmarried } \\
\text { vs married) }\end{array}$ & $1.08(0.63-1.85)$ & .79 \\
\hline Education & $0.87(0.76-0.99)$ & .03 \\
\hline $\begin{array}{l}\text { Average daily morphine- } \\
\text { equivalent dose } \mathrm{e}^{\mathrm{b}}\end{array}$ & 0.997 (0.995-0.999) & .016 \\
\hline Health plan site (GHC vs KPNC) & $1.55(1.10-2.17)$ & .012 \\
\hline Average pain severity & $1.01(0.92-1.11)$ & .89 \\
\hline \multicolumn{3}{|c|}{$\begin{array}{l}\mathrm{GHC}=\text { Group Health Cooperative; } \mathrm{KPNC}=\text { Kaiser Permanente of Northern } \\
\text { California; } \mathrm{OR}=\text { odds ratio; } \mathrm{PHQ}-8=8 \text {-item version of the Patient Health } \\
\text { Questionnaire. }\end{array}$} \\
\hline \multicolumn{3}{|c|}{$\begin{array}{l}\text { a Scored on a scale in which 0-4 = no, 5-9=mild, 10-14= moderate, and } \\
\geq 15=\text { severe depression. } \\
\text { b Per milligram. }\end{array}$} \\
\hline
\end{tabular}

Table 4. Adjusted Odds Ratio for Nonadherence Relative to Depression and Demographics

\begin{tabular}{|c|c|c|}
\hline Effect & OR $(95 \% \mathrm{Cl})$ & $P$ Value \\
\hline \multicolumn{3}{|l|}{ PHQ-8 scores ${ }^{a}$} \\
\hline PHQ-8: $\geq 15$ vs $0-4$ & $3.13(1.91-5.12)$ & $<.001$ \\
\hline PHQ-8: $10-14$ vs $0-4$ & $2.86(1.76-4.64)$ & $<.001$ \\
\hline PHQ-8: $5-9$ vs $0-4$ & $1.93(1.259-2.95)$ & $<.001$ \\
\hline Age & $0.98(0.96-0.99)$ & .80 \\
\hline Sex (female vs male) & $1.00(0.98-1.01)$ & .12 \\
\hline Race (nonwhite vs white) & $0.76(0.54-1.07)$ & .25 \\
\hline $\begin{array}{l}\text { Marital status (nonmarried } \\
\text { vs married) }\end{array}$ & $0.77(0.49-1.20)$ & .32 \\
\hline Education & $0.76(0.45-1.31)$ & .55 \\
\hline $\begin{array}{l}\text { Average daily morphine- } \\
\text { equivalent dose } \mathrm{e}^{\mathrm{b}}\end{array}$ & $0.96(0.86-1.09)$ & .56 \\
\hline Health plan site (GHC vs KPNC) & $1.00(1.00-1.00)$ & .75 \\
\hline Average pain severity & $1.10(1.01-1.21)$ & $.032^{\mathrm{b}}$ \\
\hline \multicolumn{3}{|c|}{$\begin{array}{l}\mathrm{GHC}=\text { Group Health Cooperative; KPNC }=\text { Kaiser Permanente of Northern } \\
\text { California; OR = odds ratio; PHQ- } 8=8 \text {-item version of the Patient Health } \\
\text { Questionnaire. }\end{array}$} \\
\hline \multicolumn{3}{|c|}{$\begin{array}{l}\text { a Scored on a scale in which 0-4 =no, 5-9= mild, } 10-14=\text { moderate, and } \\
\geq 15=\text { severe depression. } \\
\text { b Per milligram. }\end{array}$} \\
\hline
\end{tabular}

were only a preliminary measure of opioid misuse i $_{i}$ more extensive and internally consistent opioid misuse measures are needed. Our definition of opioid misuse was broad. A relatively high proportion of patients who were not depressed engaged in non-pain symptom misuse. This finding may be because sleep distur-

\begin{tabular}{|c|c|c|}
\hline Effect & OR $(95 \% \mathrm{CI})$ & $\begin{array}{c}P \\
\text { Value }\end{array}$ \\
\hline \multicolumn{3}{|l|}{ PHQ-8 scores ${ }^{\mathrm{a}}$} \\
\hline PHQ-8: $\geq 15$ vs $0-4$ & $1.80(0.93-3.46)$ & .080 \\
\hline PHQ-8: $10-14$ vs $0-4$ & $1.74(0.90-3.32)$ & .10 \\
\hline PHQ-8: $5-9$ vs $0-4$ & $0.79(0.44-1.42)$ & .43 \\
\hline Age & $0.97(0.95-0.99)$ & $<.001$ \\
\hline Sex (female vs male) & $1.02(0.65-1.61)$ & .93 \\
\hline Race (nonwhite vs white) & $0.43(0.24-0.79)$ & $<.001$ \\
\hline $\begin{array}{l}\text { Marital status (nonmarried } \\
\text { vs married) }\end{array}$ & $1.01(0.52-1.93)$ & .99 \\
\hline Education & $0.82(0.71-0.96)$ & .013 \\
\hline $\begin{array}{l}\text { Average daily morphine- } \\
\text { equivalent dose } \mathrm{e}^{\mathrm{b}}\end{array}$ & $0.998(0.995-1.000)$ & .026 \\
\hline Health plan site (GHC vs KPNC) & $0.69(0.44-1.08)$ & .10 \\
\hline Average pain severity & $0.94(0.83-1.07)$ & .34 \\
\hline \multicolumn{3}{|c|}{$\begin{array}{l}\mathrm{GHC}=\text { Group Health Cooperative; } \mathrm{KPNC}=\text { Kaiser Permanente of Northern } \\
\text { California; OR }=\text { odds ratio; PHQ- } 8=8 \text {-item version of the Patient Health } \\
\text { Questionnaire. }\end{array}$} \\
\hline \multicolumn{3}{|c|}{$\begin{array}{l}\text { a Scored on a scale in which 0-4 = no, 5-9= mild, } 10-14=\text { moderate, and } \\
\geq 15=\text { severe depression. } \\
\text { b Per milligram. }\end{array}$} \\
\hline
\end{tabular}

bance and stress are common in patients with chronic noncancer pain. Patients may regard using opioids to relieve these symptoms as a legitimate way to treat the effects of pain rather than as a form of misuse. It is possible that some patients with SUDs were misclassified because our study relied on self-report and automated data. The response rates in this study, which were not optimal, may be partly because many patients on COT are functionally disabled, which is generally associated with lower response rates. Despite reassurance that no survey information would be communicated to health care clinicians, some respondents may have been concerned about jeopardizing their access to COT. Our estimated misuse associations may be conservative given the nature of self-reported data.

In conclusion, clinicians should be alert to the risk of patients with depressive symptoms using their opioids to relieve those symptoms. At this point, it is not clear whether opioids are substituting for, or even disrupting, the appropriate treatment of depression. Although patients and perhaps clinicians may think that relieving pain with opioid medications will also alleviate symptoms of depression, there is no evidence from controlled trials that opioids are adequate treatment for depression. Our study shows that unrelieved depressive symptoms increase risk for opioid misuse when defined as using opioids for stress or sleep and using more than prescribed. Clinicians should consider psychiatric consultation if depressive symptoms 


\section{Figure 1. Percentage of weighted positive misuse in relationship to depression score.}

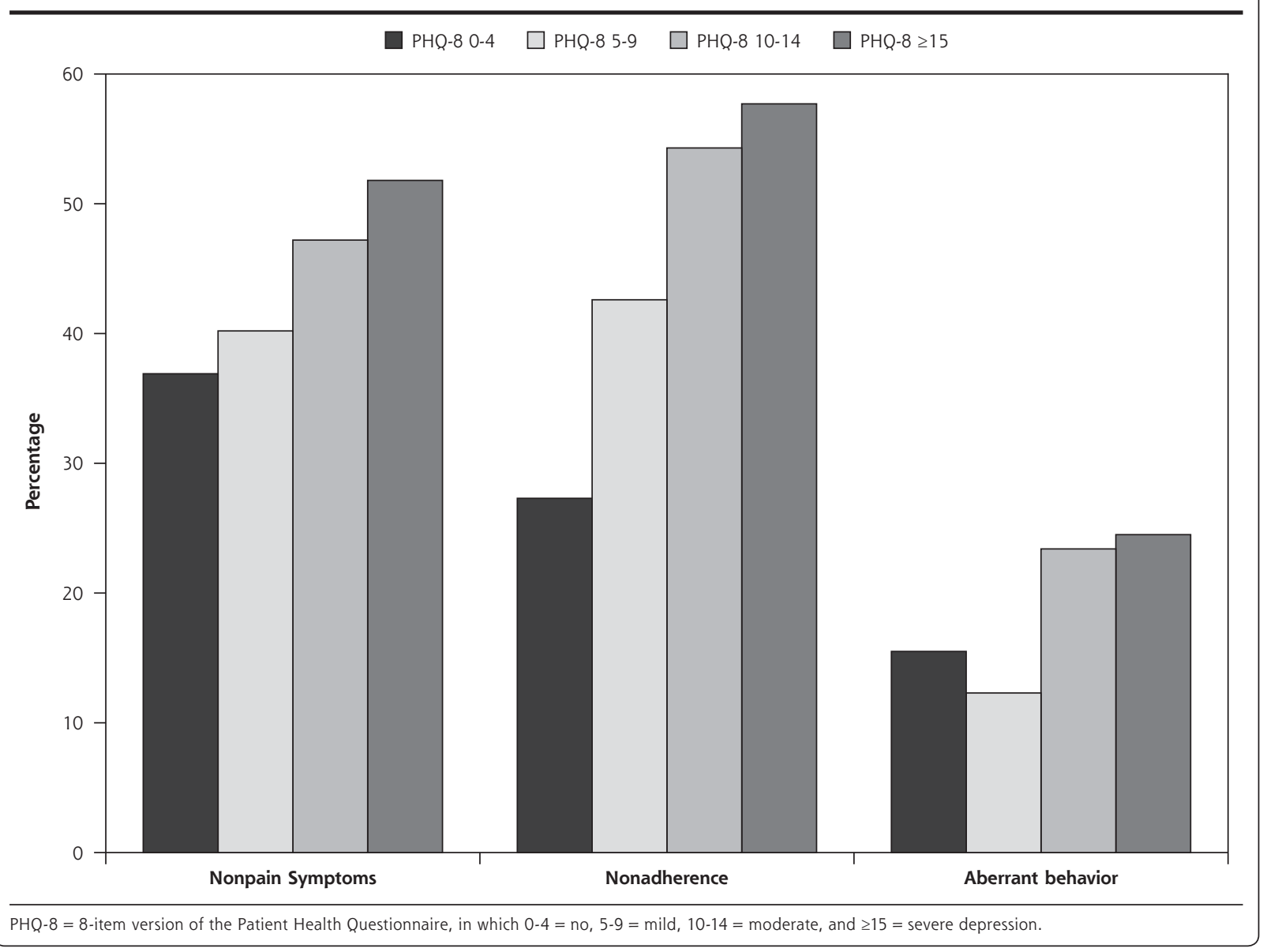

persist despite treatment. Several studies have found that severe chronic pain makes depression more treatment resistant. ${ }^{40,41}$ Our study suggests that if depressed patients are not in full remission, they remain at increased risk of opioid misuse. In light of the correlation between misuse and overdose, ${ }^{3,4}$ this population of depressed patients on COT is likely at even higher risk for overdose, either accidental or intentional. All these factors increase the necessity and the urgency of effective depression treatment in patients treated with COT. Future prospective and randomized studies should examine whether treatment of depression decreases the risk of opioid misuse.

To read or post commentaries in response to this article, see it online at http://www.annfammed.org/content/10/4/304.

Key words: depression; opioid misuse; chronic pain, opioid therapy

Submitted March 29, 2011; submitted, revised, September 15, 2011; accepted October 11, 2011.

Funding support: This research was supported by National Institute for Drug Abuse, grant R01 DA022557 (Von Korff).

\section{References}

1. Centers for Disease Control and Prevention (CDC). Increase in poisoning deaths caused by non-illicit drugs-Utah, 1991-2003. MMWR Morb Mortal Wkly Rep. 2005;54(2):33-36.

2. Ballesteros MF, Budnitz DS, Sanford CP, Gilchrist J, Agyekum GA, Butts J. Increase in deaths due to methadone in North Carolina. JAMA. 2003;290(1):40.

3. Sullivan MD, Edlund MJ, Fan MY, Devries A, Brennan Braden J, Martin BC. Risks for possible and probable opioid misuse among recipients of chronic opioid therapy in commercial and medicaid insurance plans: The TROUP Study. Pain. 2010;150(2):332-339.

4. Denisco RA, Chandler RK, Compton WM. Addressing the intersecting problems of opioid misuse and chronic pain treatment. Exp Clin Psychopharmacol. 2008;16(5):417-428.

5. National Institute on Drug Abuse. Pain and Opiophobia. Research Report Series-Prescription Drugs: Abuse and Addiction. http://www. drugabuse.gov/publications/research-reports/prescription-drugs.

6. Smith RC, Frank C, Gardiner JC, Lamerato L, Rost KM. Pilot study of a preliminary criterion standard for prescription opioid misuse. Am J Addict. 2010;19(6):523-528.

7. Morasco BJ, Dobscha SK. Prescription medication misuse and substance use disorder in VA primary care patients with chronic pain. Gen Hosp Psychiatry. 2008;30(2):93-99.

8. Braker LS, Reese AE, Card RO, Van Howe RS. Screening for potential prescription opioid misuse in a Michigan Medicaid population. Fam Med. 2009;41(10):729-734. 
9. Butler SF, Budman SH, Fernandez KC, et al. Development and validation of the Current Opioid Misuse Measure. Pain. 2007;130(1-2): 144-156.

10. Katon WJ. Epidemiology and treatment of depression in patients with chronic medical illness. Dialogues Clin Neurosci. 2011;13(1):7-23.

11. Von Korff M, Simon G. The relationship between pain and depression. Br J Psychiatry Suppl. 1996;(30):101-108.

12. Gureje O, Simon GE, Von Korff M. A cross-national study of the course of persistent pain in primary care. Pain. 2001;92(1-2):195-200.

13. Cowan DT, Wilson-Barnett J, Griffiths P, Allan LG. A survey of chronic noncancer pain patients prescribed opioid analgesics. Pain Med. 2003;4(4):340-351.

14. Breckenridge J, Clark JD. Patient characteristics associated with opioid versus nonsteroidal anti-inflammatory drug management of chronic low back pain. J Pain. 2003;4(6):344-350.

15. Sullivan MD, Edlund MJ, Zhang L, Unützer J, Wells KB. Association between mental health disorders, problem drug use, and regular prescription opioid use. Arch Intern Med. 2006;166(19):2087-2093.

16. Sullivan MD, Edlund MJ, Steffick D, Unützer J. Regular use of prescribed opioids: association with common psychiatric disorders. Pain. 2005;119(1-3):95-103.

17. Turk DC, Okifuji A. What factors affect physicians' decisions to prescribe opioids for chronic noncancer pain patients? Clin J Pain. 1997;13(4):330-336.

18. Braden JB, Sullivan MD, Ray GT, et al. Trends in long-term opioid therapy for noncancer pain among persons with a history of depression. Gen Hosp Psychiatry. 2009;31(6):564-570.

19. Edlund MJ, Martin BC, Devries A, Fan MY, Braden JB, Sullivan MD Trends in use of opioids for chronic noncancer pain among individuals with mental health and substance use disorders: the TROUP study. Clin J Pain. 2010;26(1):1-8.

20. Schieffer BM, Pham Q, Labus J, et al. Pain medication beliefs and medication misuse in chronic pain. J Pain. 2005;6(9):620-629.

21. Reid MC, Engles-Horton LL, Weber MB, Kerns RD, Rogers EL, O'Connor PG. Use of opioid medications for chronic noncancer pain syndromes in primary care. J Gen Intern Med. 2002;17(3):173-179.

22. Dunn KM, Saunders KW, Rutter CM, et al. Opioid prescriptions for chronic pain and overdose: a cohort study. Ann Intern Med. 2010;152(2):85-92.

23. Weisner CM, Campbell Cl, Ray GT, et al. Trends in prescribed opioid therapy for non-cancer pain for individuals with prior substance use disorders. Pain. 2009;145(3):287-293. Epub2009Jul5.

24. Korff MV, Saunders K, Thomas Ray G, et al. De facto long-term opioid therapy for noncancer pain. Clin J Pain. 2008;24(6):521-527.

25. Saunders K, Davis R, Stergachis A. Group health cooperative. In: Strom B, editor. Pharmacoepidemiology. 4th ed. New York: Wiley; 2005:221-239.
26. Selby J, Smith D, Johnson E, Raebel M, Friedman G, McFarland B. Kaiser Permanente Medical Care Program. In: Strom BL, editor. Pharmacoepidemiology. 4th ed. New York: Wiley; 2005:241-259.

27. Agency Medical Director's Group (AMDG). Opioid dosing guideline for chronic non-cancer pain, opioid dose calculator. http://www. agencymeddirectors.wa.gov/opioiddosing.asp.

28. Kroenke K, Strine TW, Spitzer RL, Williams JB, Berry JT, Mokdad $\mathrm{AH}$. The PHQ-8 as a measure of current depression in the general population. J Affect Disord. 2009;114(1-3):163-173.

29. Von Korff M, Ormel J, Keefe FJ, Dworkin SF. Grading the severity of chronic pain. Pain. 1992;50(2):133-149.

30. Turk DC, Swanson KS, Gatchel RJ. Predicting opioid misuse by chronic pain patients: a systematic review and literature synthesis. Clin J Pain. 2008;24(6):497-508.

31. Katz NP, Sherburne S, Beach M, et al. Behavioral monitoring and urine toxicology testing in patients receiving long-term opioid therapy. Anesth Analg. 2003;97(4):1097-1102.

32. Smith H, Passik S. Pain and Chemical Dependency. New York, NY: Oxford University Press; 2008.

33. Jackson S. Melancholia and Depression. New Haven, NY: Yale University Press; 1986.

34. Bodkin JA, Zornberg GL, Lukas SE, Cole JO. Buprenorphine treatment of refractory depression. J Clin Psychopharmacol. 1995;15(1):49-57.

35. Koran LM, Aboujaoude E, Bullock KD, Franz B, Gamel N, Elliott M. Double-blind treatment with oral morphine in treatment-resistant obsessive-compulsive disorder. J Clin Psychiatry. 2005;66(3):353-359.

36. Tenore PL. Psychotherapeutic benefits of opioid agonist therapy. J Addict Dis. 2008;27(3):49-65.

37. Katon W, Sullivan M, Walker E. Medical symptoms without identified pathology: relationship to psychiatric disorders, childhood and adult trauma, and personality traits. Ann Intern Med. 2001; 134(9 Pt 2):917-925.

38. Breivik H. Opioids in chronic non-cancer pain, indications and controversies. Eur J Pain. 2005;9(2):127-130.

39. Park J, Lavin R. Risk factors associated with opioid medication misuse in community-dwelling older adults with chronic pain. Clin J Pain. 2010;26(8):647-655.

40. Lin EHB, Tang L, Katon W, Hegel MT, Sullivan MD, Unützer J. Arthritis pain and disability: response to collaborative depression care. Gen Hosp Psychiatry. 2006;28(6):482-486.

41. Thielke SM, Fan MY, Sullivan M, Unützer J. Pain limits the effectiveness of collaborative care for depression. Am J Geriatr Psychiatry. 2007;15(8):699-707 